\title{
Pendampingan dalam Memasarkan Produk Hasil Usaha UKM melalui Penggunaan Media Sosial di Kabupaten Gunung Mas Kalimantan Tengah
}

\section{Luluk Tri Harinie}

Department of Management, Economics and Business Faculty, University of Palangka Raya E-mail: luluk3harinie@feb.upr.ac.id

\author{
Alexandra Hukom \\ Department of Economics, Economics and \\ Business Faculty, University of Palangka Raya \\ E-mail: alexandrahukom@feb.upr.ac.id
}

\section{Juma'eh}

Student of the Master of Economics, University of Palangka Raya

E-mail: hjumaeh@gmail.com

\section{Article History:}

Received: 2020-01-15

Revised: 2020-03-27

Accepted: 2020-05-31

\begin{abstract}
The purpose of this Community Service or Pengabdian kepada Masyarakat (PKM) activity was to improve the capabilities and skills of the marketing aspects of business products, especially with regard to the ability and skills to create business product promotions using online media. The results of these tools will later be shared through the chat application on Social Media with web.whatsapp.com in order to improve business. Therefor, it can expand the area of marketing the results of business products with a relatively faster and cheaper cost, even without promotion cost at all. The implementation of activities was in Gunung Mas Regency, Central Kalimantan Province, involving 6 SMEs who became PKM Partners. The method of carrying out activities was by directly visiting the business locations of each PKM partner for socialization activities, training, mentoring and discussing, and evaluation monitoring. The result indicated that PKM Partners became skilled at promoting business products as well as able to also promote through chat applications on social media by web.whatsapp.com.
\end{abstract}

Keywords: Promoting Business Products, Improve Business, Applications on Social Media

\section{Pendahuluan}

Kegiatan kewirausahaan sebenarnya memiliki pengaruh yang sangat besar bagi terwujudnya kemakmuran suatu Negara. Mengapa? Karena kegiatan kewirausahaan diyakini mampu menggerakkan ekonomi masyarakat menuju ke arah ekonomi yang 
lebih maju di masa depan ${ }^{1}$. Negara yang memiliki banyak pengusaha atau wirausahawan berpotensi cepat menjadi maju (perekonomiannya) dan menjadi negara makmur². Sementara untuk disebut negara makmur, sebuah negara harus mempunyai wirausahawan setidaknya $2 \%$ dari total jumlah penduduk. Kenyataannya, Indonesia baru memiliki 0,18\% wirausahawan dari 237 juta penduduknya 3 . Padahal Pemerintah melalui Undang-undang Republik Indonesia Nomor 20 Tahun 2008 tentang UMKM yang tertuang pada pasal 1 ayat 10 menyatakan bahwa pengembangan adalah upaya yang dilakukan oleh Pemerintah, Pemerintah Daerah, Dunia Usaha, dan masyarakat untuk memberdayakan UMKM melalui pemberian fasilitas, bimbingan, pendampingan, dan bantuan perkuatan untuk menumbuhkan dan meningkatkan kemampuan daya saing UMKM. ${ }^{4}$

Mengembangkan kemampuan daya saing UMKM baik di daerah Perkotaan maupun di tingkat Kabupaten dan Desa memang harus terus dilakukan. Hal ini pun disadari penuh oleh Pemerintan Daerah Kabupaten Gunung Mas Provinsi Kalimantan Tengah yang menyatakan bahwa pemberdayaan UMKM menjadi salah satu solusi dalam mengembangkan roda ekonomi, terutama untuk mengatasi persoalan kemiskinan, pengangguran, dan kesejangan sosial ${ }^{5}$. Terbukti sampai dengan 31 Januari 2017 tercatat jumlah UMKM sebanyak 3754 wirausahawan dengan rincian 3417 usaha mikro, 336 usaha kecil, dan 1 usaha menengah ${ }^{6}$. Jumlah UMKM tersebut bagi Pemerintah Daerah Kabupaten Gunung Mas telah memberikan rasa optimis bahwa citra wirausahawan akan semakin membaik dan tercipta wirausahawan yang berdaya saing tinggi. Sehingga dengan demikian ekonomi masyarakat akan semakin membaik pula.

Namun untuk menciptakan wirausahawan yang berdaya saing tinggi ternyata masih menghadapi kendala. Diungkapkan oleh beberapa wirausahawan di Kabupaten Gunung Mas bahwa kendala yang sering dihadapi terutama yang berkaitan dengan pemasaran akan produk hasil usahanya akibat dari persaingan usaha yang dirasa sangat tinggi. Para wirausahawan ini sebenarnya sangat berkeinginan produk hasil usahanya dapat dikenal dengan mudah oleh masyarakat sekitar. Dengan begitu usahanya dapat bertahan dan semakin berkembang.

Selanjutnya dituturkan oleh para wirausahawan bahwa sebenarnya mereka membutuhkan sebuah sarana untuk mempromosikan produk hasil usahanya. Para wirausahawan percaya melalui promosi produk hasil usaha, masyarakat akan mudah

\footnotetext{
${ }^{1}$ Robert P Singh, "The Shortage of Academically Trained Entrepreneurship Faculty: Implications, Challenges, and Opportunities," Journal of entrepreneurship education 11 (2008): 117.

2 Riant Nugroho, "Membangun Entrepreneur Indonesia," Jakarta: PT Elex Media Komputindo (2015).

${ }^{3}$ MR Zarkasyi, "Entrepreneur Radikal: Catatan Inspiratif Dan Solusi-Solusi Taktis Mengatasi Tahapan-Tahapan Kritis Dalam Bisnis" (2013).

${ }^{4}$ Presiden Republik Indonesia, Undang-Undang Republik Indonesia Nomor 20 Tahun 2008 Tentang UMKM (Indonesia, n.d.).

${ }^{5}$ Epra Sentosa, "Gunung Mas Miliki 3.754 Usaha Mikro, Kecil, Dan Menengah," Borneonews.Co.Id, last modified 2017, accessed April 4, 2019, https://www.borneonews.co.id/berita/74222-gunung-masmiliki-3-754-usaha-mikro-kecil-dan-menengah.

6 Ibid.
} 
mengenal produk hasil usaha mereka tersebut. Hanya sekarang yang menjadi persoalan kembali, untuk melakukan sebuah promosi produk hasil usaha membutuhkan biaya yang tidak sedikit dan para wirausahawan menyatakan tidak mampu untuk mewujudkannya. Melakukan promosi produk hasil usaha dirasa para wirausahawan ini akan semakin memberatkan mereka. Sementara rata-rata para wirausahawan ini masih menjadi mitra dari Unit Mikro salah satu perbankan di Kabupaten Gunung Mas Provinsi Kalimantan Tengah.

Berkenaan dengan hasil pengamatan yang telah dikemukakan, maka kegiatan pendampingan ini bertujuan untuk meningkatkan kemampuan dan keterampilan dari aspek pemasaran produk hasil usaha, terutama berkaitan dengan kemampuan dan keterampilan membuat promosi produk hasil usaha demi meningkatkan usaha. Promosi merupakan salah satu faktor penentu keberhasilan suatu program pemasaran untuk memberikan informasi mengenai adanya suatu produk ${ }^{7}$. Fokus pendampingan pada mitra PKM lebih kepada pembuatan model promosi produk hasil usaha yang nantinya disebarkan melalui penggunaan media sosial. Hal ini sesuai dengan hasil penelitian Nurgiyantoro ${ }^{8}$ yang menyatakan promosi melalui media sosial (medsos) berpengaruh positif dan signifikan terhadap keputusan pembelian konsumen. Jaringan dalam media sosial ini menjadi bentuk baru komunikasi intensif antara "consumer to consumer ( $C$ to $C)$ " dan "business to consumer ( $B$ to $C$ )" yang memiliki berdampak besar terhadap pemasaran ${ }^{9}$. Pemasaran dengan media sosial mampu menciptakan hubungan sosial yang lebih personal dan dinamis dibandingkan dengan strategi pemasaran tradisional ${ }^{10}$.

Merujuk dari apa yang telah diungkapkan, maka kegiatan pengabdian kepada masyarakat (PKM) ini sebagai suatu kegiatan pendampingan yang melibatkan enam wirausahawan UMKM yang menjadi Mitra PKM dan kesemuanya berlokasi di Kabupaten Gunung Mas Provinsi Kalimantan Tengah. Akhirnya melalui kegiatan PKM ini diharapkan dapat memberi manfaat bagi mitra PKM sebagai salah satu alternatif bagi pemasaran produk hasil usaha dengan area jangkauan pemasaran lebih luas, dengan waktu yang relatif lebih cepat, murah biayanya atau bahkan tanpa mengeluarkan biaya promosi sama sekali

\section{Metode}

Kegiatan pengabdian kepada masyarakat (PKM) ini dilakukan di Kabupaten Gunung Mas Provinsi Kalimantan Tengah. Tim PKM akan langsung berkunjung ke lokasi usaha masing-masing mitra PKM dengan skema waktu pendampingan dilakukan di

7 Tjiptono Fandy, Strategi Pemasaran Edisi 3 (Yogyakarta: ANDI, 2008).

${ }^{8}$ Singgih Nurgiyantoro, "Pengaruh Strategi Promosi Melalui Social Media Terhadap Keputusan Pembelian Garskin Yang Dimediasi Word of Mouth Marketing (Studi Pada Konsumen Produk Garskin Merek SayHello Di Kota Yogyakarta)," Skripsi, tidak diterbitkan, Program Studi Manajemen Fakultas Ekonomi Universitas Negeri Yogyakarta (2014).

${ }^{9}$ Philip Kotler and Keller, Marketing Management (Prentice Hall: Pearson Education, 2012). 2011).

${ }^{10}$ Joseph Devito, “Komunikasi Antar Manusia. Tanggerang Selatan” (Karisma Publishing Group, 
sela-sela kesibukan para wirausahawan yang menjadi mitra PKM. Pendekatan PKM ini menggunakan service learning, dengan melalui tiga tahapan, yakni tahapan persiapan, tahapan melayani, dan tahapan refleksi. ${ }^{11}$ Adapun dalam tahap melayani, sistem pendampingan yang diterapkan oleh Tim PKM menggunakan pembelajaran tutorial. Menurut Munir ${ }^{12}$ interaksi pembelajaran berbentuk tutorial merupakan pengetahuan dan informasi dikomunikasikan atau disajikan dalam bentuk unit-unit kecil disertai dengan pertanyaan-pertanyaan. Sehingga sistem pembelajaran yang dilakukan Tim PKM selama 6 hari untuk enam mitra PKM. Artinya dalam satu hari tim PKM akan memberikan pembelajaran pada satu mitra PKM dengan alokasi waktu 4 jam per pertemuan.

Jangka waktu pelaksanaan kegiatan Pengabdian Kepada Masyarakat (PKM) selama 4 bulan. Adapun mitra dampingan sebanyak enam wirausahawan sebagaimana tersaji dalam tabel berikut:

Tabel 1 Data Mitra PKM

\begin{tabular}{|c|c|c|c|}
\hline No. & $\begin{array}{l}\text { Nama Pemilik } \\
\text { Usaha }\end{array}$ & Nama Usaha & Alamat Tempat Usaha \\
\hline 1. & Daniel & $\begin{array}{l}\text { Home Industry } \\
\text { Creatif Anak Lewu }\end{array}$ & $\begin{array}{l}\text { Jl. Langsat, RT 05/RW 02, Tampang, } \\
\text { Tumbang Anjir }\end{array}$ \\
\hline 2. & Harmuda/Uda & Kerajinan Kacapi & $\begin{array}{l}\text { Jl. Damang Swang No. 14 RT 03/RW } \\
\text { 01, Tumbang Anjir }\end{array}$ \\
\hline 3. & Endang & Fotocopy Erikson & $\begin{array}{l}\text { Jl. Damang Sawang RT 02, Tumbang } \\
\text { Anjir }\end{array}$ \\
\hline 4. & Mama Noval & Penjahit Nayla & Jl. Letjen Soeprapto, Kuala Kurun \\
\hline 5. & Koleng & Sembako Ardim & Jl. Mangku Rambang, Tumbang Anjir \\
\hline 6. & Oeng Tenun & Kerajinan Jawet & Jl. Mangku Rambang, Tumbang Anjir \\
\hline
\end{tabular}

\section{Hasil Pendampingan dan Pembahasan}

Pelaksanaan pendampingan dengan pendekatan service learning ini dilakukan dalam tiga tahap, yakni tahap persiapan, tahap melayani, dan tahap refleksi. Dalam tahap persiapan, Tim PKM melakukan koordinasi dan sosialisasi program kepada mitra dampingan di Kabupaten Gunung Mas Provinsi Kalimantan Tengah dengan langsung berkunjung ke lokasi usaha masing-masing.

Strategi kunjung langsung dipilih sebagai bagian agar Tim PKM dapat langsung berinteraksi dengan mitra dampingan, baik untuk melihat bagaimana kondisi eksisting

${ }^{11}$ Irene Nusanti, "Strategi Service Learning Sebuah Kajian Untuk Mengembangkan Kegiatan Pembelajaran," Jurnal Pendidikan dan Kebudayaan 20, no. 2 (2014): 251-260, accessed May 31, 2020, http://up.openjournaltheme.com/jurnaldikbud/ojs-3.1.2-4/index.php/jpnk/article/view/142.

12 Multimedia Munir, "Multimedia Konsep \& Aplikasi Dalam Pendidikan," Bandung. CV. Afabeta (2012). 
mitra dampingan, baik terkait jenis usaha, kualitas produk, kualitas layanan, serta model pemasaran produk usaha yang sudah dilakukan dengan mitra. Selain itu, melalui tahap ini juga diketahui apakah mitra sudah memanfaatkan media social dalam pemasaran produk mereka, dan bagaimana model yang sudah dilakukan mitra apabila sudah menggunakan media social dalam strategi pemasarannya. Tahap ini sebagaimana terlihat dalam gambar berikut:
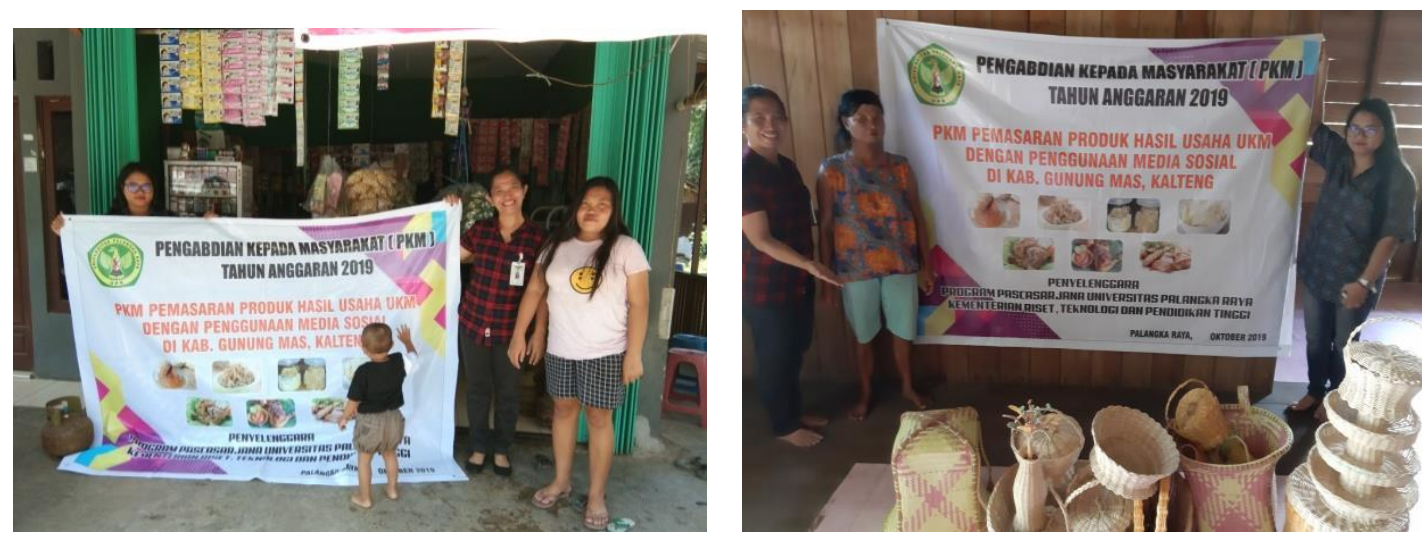

Gambar 1. Tim PKM melakukan kunjung langsung dan sosialisasi pada Mitra PKM

Tahap selanjutnya adalah tahap melayani. Dalam tahap ini, Tim pendamping melakukan layanan melalui tutorial kepada masing-masing mitra PKM satu per satu di lokasi usaha mitra. Hal ini dimaksudkan agar dalam tahap layanan ini mitra tetap nyaman untuk belajar bersama dalam pemasaran hasil produk usaha mereka. Selain itu, mitra juga akan dapat langsung memahami bagaimana strategi pemasaran melalui media social yang cocok sesuai karakter usaha mereka, karena Tim PKM dan mitra dapat melihat langsung beragam produk yang sudah dihasilkan oleh mitra untuk dipromosikan melalui media sosial.

Agar proses tutorial bisa berjalan efektif, Tim PKM menggunakan modul pembelajaran yang telah disusun sebagai media pembelajaran bersama untuk mempermudah dalam memberikan penjelasan kepada mitra PKM. Mengingat pembuatan model promosi produk hasil usaha menggunakan suatu sarana online yang nantinya dibagikan (di-share) melalui aplikasi chatting pada Media Sosial dengan web.whatsapp.com. Berikut gambar modul pembelajaran dan sistem pembelajaran yang diterapkan Tim PKM secara tutorial pada kegiatan PKM ini.

Dari modul yang sudah disusun, Tim PKM melakukan pelatihan kepada mitra secara tutorial satu persatu, dimulai dengan pengenalan model promosi produk hasil usaha, khususnya promosi melalui media sosial. Selain itu, dalam sessi ini, para mitra juga dapat melakukan diskusi intensif untuk menghasilkan model promosi yang menarik dan mudah diingat oleh konsumennya sesuai dengan produk usaha mereka masing-masing. 

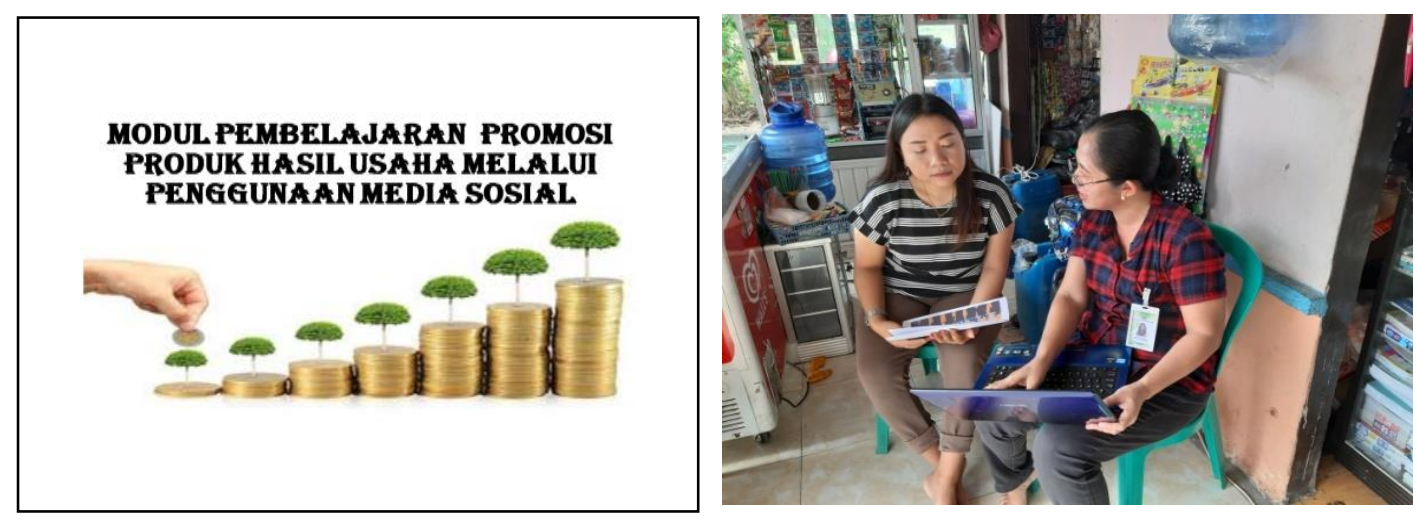

Gambar 2. Kegiatan Pelatihan oleh Tim PKM pada salah satu mitra PKM "Home Industry Creatif Anak Lewu"

Melalui model tutorial satu persatu dari mitra dampingan, para mitra dapat secara langsung belajar dan mempraktekkan promosi produk usaha mereka melalui media social. Mereka juga merasakan, bahwa dalam promosi melalui media social ini memerlukan sebuah kreatifitas dan kepercayaan diri yang tinggi, sehingga sangat diperlukan sekali dorongan secara psikologis bagi Mitra PKM untuk membangkitkan semangat akan kemampuan yang dimiliki diri sendiri.
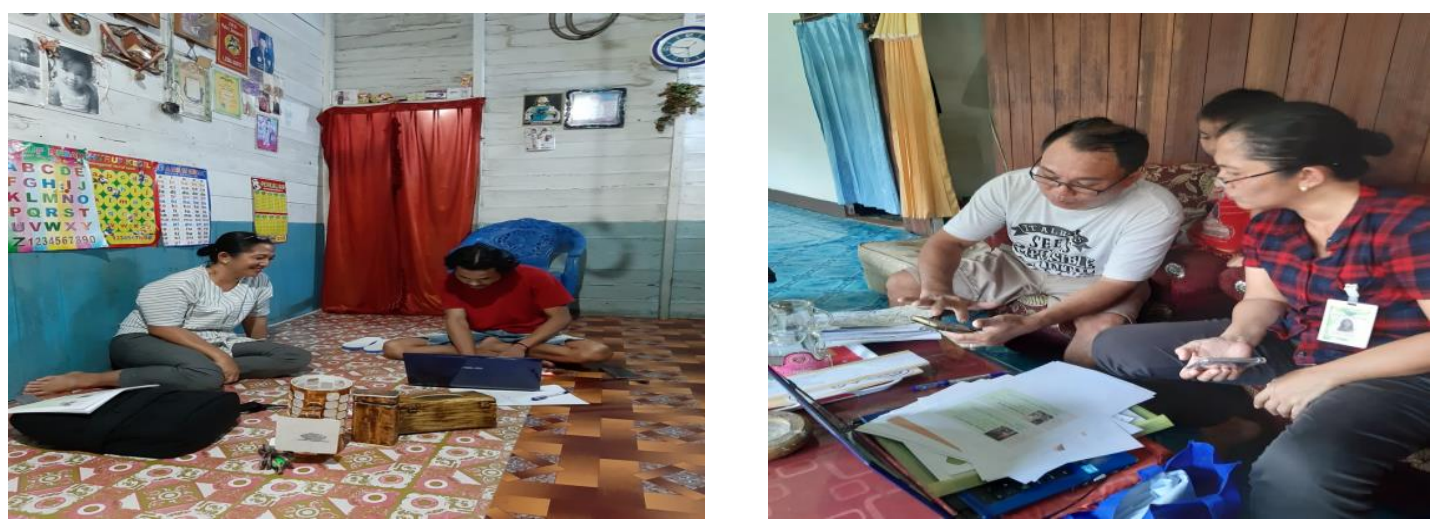

Gambar 3. Praktek Promosi Produk melalui Media Sosial

Hasil dari kegiatan PKM ini dapat terlihat pada kegiatan pelaksanaan monitoring dan evaluasi bagi kegiatan PKM, terutama untuk mengukur tingkat pemahaman terhadap penguasaan sarana online bagi promosi produk hasil usaha yang dibagikan (di-share) melalui aplikasi chatting pada Media Sosial dengan web.whatsapp.com. Berikut luaran yang dihasilkan dari kegiatan PKM berbentuk Promosi Produk yang dibuat oleh Mitra UKM. 


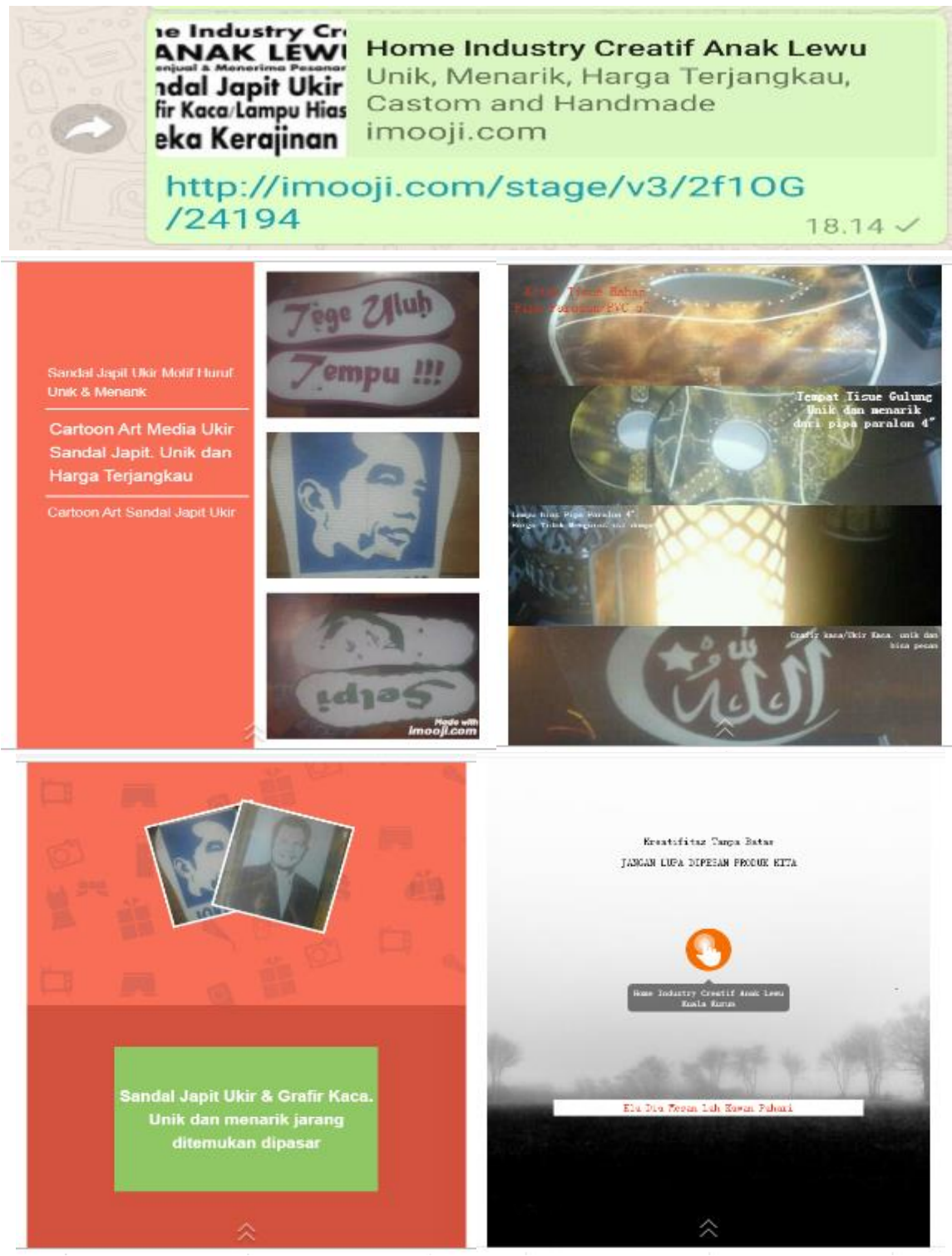

Gambar 4. Model Promosi Produk yang dibuat oleh salah satu Mitra UKM.

Dari gambar 4 di atas, terlihat hasil bagaimana mitra dampingan telah membuat berbagai model promosi produk hasil usaha dengan gambar-gambar dan kata-kata yang menarik. Dengan model promosi yang sudah dikembangkan, para wirausahawan mitra PKM telah memiliki kemampuan dan kemahiran yang cukup baik dalam membuat promosi produk yang simple dan menarik dengan memadukan gambar produk dan kata-kata yang mudah difahami, sehingga menarik masyarakat untuk membaca dan memahmi isi pesan yang dibagikan melalui chatting media social.

Selanjutnya, pada tahap akhir adalah refleksi dan evaluasi akhir dari kegiatan PKM. Dari proses implementasi tahap layanan melalui tutorial dan praktek langsung promosi produk melalui media social, didapatkan hasil bahwa model pendampingan ini sangat bermanfaat bagi mereka. Hal ini sebagaimana diungkapkan oleh Harnuda dan Daniel yang menyatakan bahwa model promosi produk melalui media social ini sangat 
membantu mereka, mengingat mereka belum pernah sama sekali melakukan promosi bagi produk hasil usahanya. Melalui media social, mereka dapat melalukan promosi dengan kreatif dengan low budget. Oeng Tenun, mitra dampingan yang bergerak di kerajinan Jawet juga mengungkapkan bahwa promosi melalui media social ini terbukti mampu meningkatkan volume penjualan produk mereka dibanding bulan-bulan sebelumnya.

Dari proses pendampingan di atas, pendampingan dalam promosi produk melalui media social memiliki manfaat yang sangat baik bagi mitra dampingan. Dengan pednekatan service learning, mitra dampingan telah mampu membuat promosi yang baik serta telah merasakan ada peningkatan volume penjualan produk-produk usaha mereka dengan low budget, namun efektif dan langsung dapat berinteraksi dengan konsumen produk mereka. Hal ini sesuai dengan kajian Dedi Rianto Rahadi, Leon Andretti Abdillah yang menyatakan bahwa para pengrajin handycraft di Palembang $35 \%$ pengrajin telah memanfaatkan media social sebagai sarana promosi produk mereka. Alasan mereka menggunakan media sosial sebagai sarana promosi karena (1) biaya minimal, (2) mudah dikenali, (3) area distribusi global. Promosi produk melalui media sosial juga bisa membangun komunikasi yang baik dengan pelanggan mereka. ${ }^{13}$

Terkait dengan volume penjualan yang naik pasca melakukan promosi melalui media social, juga selaras dengan kajian Deru R. Indika dan Cindy Jovita yang menyatakan bahwa promosi melalui media social instagram mampu meningkatkan minat beli sebesar $50,2 \%$. $^{14}$

\section{Kesimpulan}

Kegiatan pengabdian kepada masyarakat (PKM) di Kabupaten Gunung Mas Provinsi Kalimantan Tengah yang dilaksanakan oleh Tim PKM melalui beberapa tahapan secara teknis telah dilaksanakan dengan baik dan sesuai jadwal kegiatan PKM. Hal ini terlihat dari hasil pelaksanaan monitoring dan evaluasi bahwa para wirausahawan mitra PKM sudah mampu serta mahir dalam membuat model promosi produk hasil usaha dengan gambar-gambar dan kata-kata yang menarik. Kegiatan ini pun membawa dampak bagi peningkatan penjualan produk mereka dibanding bulanbulan sebelumnya.

Disadari kegiatan PKM semacam ini ternyata sangat diperlukan oleh masyarakat bagi peningkatan kesejahteraannya, sehingga disarankan kegiatan semacam ini perlu untuk dilanjutkan guna menjangkau lebih banyak UKM di daerah yang lain.

\footnotetext{
${ }^{13}$ Dedi Rianto Rahadi and Leon Andretti Abdillah, "The Utilization of Social Networking as Promotion Media (Case Study: Handicraft Business in Palembang)," in SESIND02013 Conference. Seminar Nasional Sistem Informasi Indonesia (SESINDO) (Bali: arXiv.org, 2013), accessed May 31, 2020, http://arxiv.org/abs/1312.3532.

14 Deru R. Indika and Cindy Jovita, "MEDIA SOSIAL INSTAGRAM SEBAGAI SARANA PROMOSI UNTUK MENINGKATKAN MINAT BELI KONSUMEN," Jurnal Bisnis Terapan 1, no. 1 (2017): 25-32, accessed May 31, 2020, http://www.journal.ubaya.ac.id/index.php/JIBT/article/download/296/192.
} 


\section{Daftar Referensi}

Devito, Joseph. "Komunikasi Antar Manusia. Tanggerang Selatan." Karisma Publishing Group, 2011.

Epra Sentosa. "Gunung Mas Miliki 3.754 Usaha Mikro, Kecil, Dan Menengah." Borneonews.Co.Id. Last modified 2017. Accessed April 4, 2019. https://www.borneonews.co.id/berita/74222-gunung-mas-miliki-3-754-usahamikro-kecil-dan-menengah.

Fandy, Tjiptono. Strategi Pemasaran Edisi 3. Yogyakarta: ANDI, 2008.

Indika, Deru R., and Cindy Jovita. "MEDIA SOSIAL INSTAGRAM SEBAGAI SARANA PROMOSI UNTUK MENINGKATKAN MINAT BELI KONSUMEN." Jurnal Bisnis Terapan 1, no. 1 (2017): 25-32. Accessed May 31, 2020. http://www.journal.ubaya.ac.id/index.php/JIBT/article/download/296/192.

Kotler, Philip, and Keller. Marketing Management. Prentice Hall: Pearson Education, 2012.

Munir, Multimedia. "Multimedia Konsep \& Aplikasi Dalam Pendidikan." Bandung. CV. Afabeta (2012).

Nugroho, Riant. "Membangun Entrepreneur Indonesia." Jakarta: PT Elex Media Komputindo (2015).

Nurgiyantoro, Singgih. "Pengaruh Strategi Promosi Melalui Social Media Terhadap Keputusan Pembelian Garskin Yang Dimediasi Word of Mouth Marketing (Studi Pada Konsumen Produk Garskin Merek SayHello Di Kota Yogyakarta)." Skripsi, tidak diterbitkan, Program Studi Manajemen Fakultas Ekonomi Universitas Negeri Yogyakarta (2014).

Nusanti, Irene. "Strategi Service Learning Sebuah Kajian Untuk Mengembangkan Kegiatan Pembelajaran." Jurnal Pendidikan dan Kebudayaan 20, no. 2 (2014): 251260. Accessed May 31, 2020. http://up.openjournaltheme.com/jurnaldikbud/ojs3.1.2-4/index.php/jpnk/article/view/142.

Presiden Republik Indonesia. Undang-Undang Republik Indonesia Nomor 20 Tahun 2008 Tentang UMKM. Indonesia, n.d.

Rahadi, Dedi Rianto, and Leon Andretti Abdillah. "The Utilization of Social Networking as Promotion Media (Case Study: Handicraft Business in Palembang)." In SESIND02013 Conference. Seminar Nasional Sistem Informasi Indonesia (SESINDO). Bali: arXiv.org, 2013. Accessed May 31, 2020. http://arxiv.org/abs/1312.3532.

Singh, Robert P. "The Shortage of Academically Trained Entrepreneurship Faculty: Implications, Challenges, and Opportunities." Journal of entrepreneurship education 11 (2008): 117.

Zarkasyi, MR. "Entrepreneur Radikal: Catatan Inspiratif Dan Solusi-Solusi Taktis Mengatasi Tahapan-Tahapan Kritis Dalam Bisnis" (2013). 